1. Introdução: razão e importância das sociedades cooperativas;

2. Os requisitos de um programa de desenvolvimento dos recursos humanos

em cooperativas;

3. Os requisitos de um programa de desenvolvimento de estruturas administrativas em cooperativas.

\section{R. M. Garcia*}

* Professor-chefe do Departamento de Administração Geral e Recursos Humanos da EAESP/FGV.
1. INTRODUÇÃO: RAZÃO E IMPORTÂNCIA DAS SOCIEDADES COOPERATIVAS

A importância real das organizações cooperativas é uma expressão direta de seus distintos principios doutrinários e associativos. Neste sentido, as cooperativas seriam essencialmente uma organização de pessoas que, em bases democráticas, se unem com o objetivo de atender certas necessidades econômicas fundamentais. Este tipo particular de associação manifesta duas dimensões básicas: é uma instituição política (interessada na organização e promoção social de seus membros) e é, ao mesmo tempo, um empreendimento econômico (que se obriga a produzir algum bem ou serviço dentro de um grau relativo de eficiência econômica). Assim, seria precisamente esta propriedade de articular, dentro de uma mesma organização, essas duas dimensões (a política e a econômica) que confere às cooperativas seu caráter especifico. Pelo menos enquanto diretriz doutrinária, as cooperativas se propõem a ser uma solução simples e prática aos conflitos existentes entre as mencionadas características: a do cidadão, que enfatiza o bem público e a responsabilidade social, e a do ator econômico, interessado na produção eficiente de bens ou serviços. ${ }^{1}$

Desta maneira, poder-se-ia sustentar que, em uma associação cooperativa, o próprio ato de produção, ou melhor, a própria idéia do que seja trabalho inclui necessariamente características "metaeconômicas". Para se utilizar uma idéia atribuída a Mauss, $o$ ato de produção é entendido como sendo um fato social total onde, além da dimensão econômica, poderíamos incluir outras, de natureza social, política, cultural, ética, estética e - por que não? - religiosa.

Karl Polanyi e os adeptos da escola substantiva em economia chamam a atenção para o fato de que a inquestionável importância atribuída à economia é um fenômeno sócio-histórico relativamente recente. $\mathrm{Na}$ Europa do século XIX, a esfera econômica "destacase" do sistema de normas sociais, dispensando, desta maneira, o controle dos atores humanos sobre os motivos econômicos, e, ao mesmo tempo, desencadeando um processo pelo qual a razão econômica passa a dominar a sociedade em sua totalidade. ${ }^{2}$ Outros atores têm descrito esse mesmo processo como sendo a transformação mais profunda operada pela revolucão industrial que, na Inglaterra, atingiu seu apogeu no período de tempo que vai, aproximadamente, do ano 1760 ao ano 1840 .

Como reação a este estado de coisas, um grupo de tecelóes na pequena cidade de Rochdale, Inglaterra, fundou, no ano de 1844 , uma instituição que ficou conhecida pelo nome de Rochdale Society of Equitable Pioneers. Este grupo de pioneiros estabeleceu princípios de produção e métodos ou regras de operação que evidenciavam a intenção de restabelecer $a$ inteireza do ato produtivo humano (e, portanto, em flagrante contraste com as práticas economicistas da época). Na sua essência, os princípios de uma produção equitativa visavam a subordinar o motivo econô- 
mico aos ideais de solidariedade humana, conduta ética e justiça social. Os métodos ou regras de operação estabelecidos por esse grupo de tecelões obtiveram tanto sucesso, que eles passaram a ser considerados os fundadores do que é hoje conhecido como movimento cooperativista.

Segundo um especialista da Organização das Nações Unidas, M. Colombain, os novos princípios de produção estabelecidos pelas cooperativas revelariam os seguintes valores normativos fundamentais: 1. solidariedade e compromisso mútuo; 2 . igualdade; 3. prestação de serviços; 4. eqüidade; 5 . educação (ou cultura) cooperativa.

Assim, a magnífica iniciativa dos pioneiros de Rochdale manifestou-se através do objetivo declarado de construir um sistema sócio-econômico livre da exploração (terceiro valor), no qual as pessoas desfrutariam direitos iguais e teriam deveres iguais (segundo valor), distribuindo igualmente entre elas (quarto valor) os malefícios e os benefícios de sua ação social, inspiradas por um sentido próprio de solidariedade (primeiro valor), com o objetivo de valorização progressiva da espécie humana (quinto valor $){ }^{3}$

Portanto, seria a própria especificidade das cooperativas, enquanto um paradigma organizacional distinto, que permite considerá-las a mais viável alternativa às empresas comerciais típicas. Aqui, a palavra alternativa significa essencialmente o seguinte: as sociedades cooperativas têm que produzir bens e serviços dentro de uma lógica econômica predeterminada, mas, ao mesmo tempo, são incorporadas ao trabalho e produção cooperativos os já mencionados valores normativos.

Em sintese, a grande vantagem das sociedades cooperativas reside precisamente nas suas propriedades "metaeconômicas". É preciso deixar ressaltado que estamos lidando com potenciais - com o futuro e, portanto, ao descrevermos as características essenciais de uma cooperativa, deixamos de lado os casos excepcionais e episódios das falsas cooperativas e das grandes sociedades anônimas. Neste contexto, o passado já realizado, e deformado, apresenta pouca utilidade. Interessa-nos, isto sim, tentar viabilizar uma proposta que, estrutural e historicamente, apresenta um imenso potencial. Se isto for considerado, as cooperativas poderão contribuir para a resolução dos seguintes problemas: ${ }^{4}$

1. As cooperativas apresentam um grande potencial para lidar com distúrbios econômicos, como por exemplo, inflação, recessão, estagnação e desemprego.

É evidente que as cooperativas não são uma panacéia para todos os males do ser humano. Contudo, essas organizações podem prestar um grande auxílio em épocas de crise econômica. Isto porque as cooperativas estimulam a auto-ajuda, iniciativa e autonomia de seus membros. Assim, um grande número de pessoas, margnializadas e inativas pelo desemprego, seriam capazes - uma vez organizadas - de descobrir necessidades comuns e motivações similares. Através do sinergismo associativo, as pessoas acabam descobrindo que são capazes de melhorar sua situação econômica e de se libertarem do sentido de inutilidade social que sempre acompanha os momentos de impasse econômico, intensificados, em geral, pelo emprego cego de políticas econômicas convencionais. ${ }^{5}$ Creio que seria desnecessário comentarmos a miséria social causada pela destruição das formas tradicionais de vida e de organização do trabalho, provocados por um processo de acumulação econômica selvagem.

2. As cooperativas poderiam estimular a participação social de seus membros e, conseqüentemente, valorizar os recursos e condições locais de desenvolvimento.

O senso comum é de que uma participação maior nos negócios da cooperativa contribui para um maior envolvimento com os problemas da comunidade. Já que as cooperativas se fundam na associação voluntária para a resolução de interesses comuns, e uma vez que os resultados econômicos dessa associação permanecem na comunidade, as cooperativas contribuem em maior proporção para o desenvolvimento local do que as empresas comerciais típicas.

3. As cooperativas apresentam, potencialmente, maior flexibilidade estrutural em relação às mudanças econômicas.

Pode-se admitir que as cooperativas são intrinsecamente dotadas de responsabilidade social e são concebidas para responderem às necessidades específicas de seus membros. Isto significa que as cooperativas não são estruturalmente voltadas para a construção de impérios econômicos, os quais, inevitavelmente, criam a necessidade de adotarem-se políticas e práticas administrativas inerentemente conservadoras. As cooperativas, quando apresentam uma base local, têm apresentado uma impressionante capacidade para a resolução de problemas e para a inovação social.

4. As cooperativas contribuem para o aperfeiçoamento da democracia.

As cooperativas, ao desenvolverem seu potencial, são o meio organizacional ideal para a participação de pessoas que se encontram em um estado de marginalização econômica e/ou institucional. A grande contribuição de uma cooperativa é o desenvolvimento da educação cívico-política, ou melhor, essas organizações - se bem sucedidas - seriam capazes de demonstrar às chamadas pessoas comuns que é possível influir nos destinos de suas próprias vidas. Afinal de contas, os administradores, os técnicos, os líderes políticos constituem apenas a minoria de nossa sociedade. A maioria das pessoas não tem a oportunidade de participar na condução dos negócios e da vida das organizações e, ao que tudo indica, elas nem chegam a se sentir capazes de fazê-lo. ${ }^{6}$ 
5. As cooperativas exibem um melhor balanço energético.

As cooperativas têm um importante papel a cumprir na atual fase de conservação de energia. Isto porque essas organizações apresentam um consumo mais favorável de recursos não-renováveis, já que, em princípio, não estariam voltadas para a acumulação econômica desenfreada. Pela sua própria lógica, as cooperativas têm o interesse de satisfazer as necessidades de seus membros, e não de expandi-las. As cooperativas enfatizam o serviço, e não o lucro. Quando uma cooperativa necessita expandir suas atividades, existe sempre a possibilidade de fazê-lo não através do gigantismo individual e corporativo, mas da associação federativa com outras cooperativas. As cooperativas podem apresentar uma forma de crescimento que se poderia chamar, na falta de um nome melhor, de "modular". No crescimento "modular" os custos sociais associados à coordenação e centralização administrativas são bem mais reduzidos. ${ }^{7}$

\section{OS REQUISITOS DE UM PROGRAMA DE DESENVOLVIMENTO DOS RECURSOS HUMANOS EM COOPERATIVAS}

Vimos que o projeto cooperativista implica - no seu sentido mais profundo - uma crítica, inteligente $e$ prática, da dependência externa, contingencial, de pessoas e organizações. Nas organizações comerciais típicas, pessoas e organizações são vistas como sendo dependentes de processos deterministas de equilíbrio e de leis econômicas implacáveis. Assim, pouco resta à ação humana, que, desta maneira, se torna praticamente limitada à seleção de estímulos ambientais e à adoção dos comportamentos adequados a cada situação específica - o que significa que as pessoas vivem improvisando soluções "aceitáveis" aos problemas da "realidade", apenas sobrevivendo, por assim dizer. Elas são praticamente forçadas, de maneira inteiramente independente de sua vontade e consciência, a estabelecerem certa previsibilidade de comportamento e de travarem certas relações sociais, as quais dão - via imposição externa - sentido ao homo economicus. Este comporta-se sempre como um maximizador "racional" de interesses econômicos individuais (o que exclui a possibilidade do altruísmo, ou mesmo da inveja de atuarem como forças poderosas de motivação) e que satisfaz suas necessidades em um mundo de relativa escassez.

Neste contexto, “...o homem só é ativo na medida em que a economia é ativa e isto enquanto ela faz do homem uma certa abstração: ela estimula e ressalta algumas das possibilidades dele e se descuida de outras que são inúteis do ponto de vista do próprio funcionamento"'.8

Por outro lado, a proposta cooperativista sustenta que o homem só é verdadeiramente homem, no sentido mais completo da palavra, quando ele age. Daí o cooperativismo ter desenvolvido uma vocação política, pois por político entende-se a ação consciente e inteligente de manutenção ou transformação de estruturas sociais globais. ${ }^{9}$

$\mathrm{O}$ ator cooperativista é, assim, diferente do ator econômico. Aquele, evidentemente, leva em consideração as restrições ou limitações do seu meioambiente, mas compreende perfeitamente que existe uma tensão entre o seu projeto e o conjunto da sociedade. Que ao invés de encarar a economia como uma "segunda natureza" que o domina, vê a realidade como um conjunto dinâmico de possibilidades emergentes. Ele autodetermina-se.

Em outras palavras, consideremos, por exemplo, as características mais específicas das cooperativas, como: filiação livre e voluntária; gestão democrática (um homem, um voto); retorno limitado ao capital; distribuição do excedente econômico segundo as transações; e alocação de recursos em educação cooperativista. ${ }^{10}$ Parece-me mais do que razoável admitir que um administrador de cooperativas, para dar vida a essas características, deverá contar com talento, habilidades e qualificações profissionais especiais. Ele não poderá ser um mero apêndice do capital, definido por condições externas a si mesmo, dócil e ajustado aos determinismos das leis econômicas inexoráveis ou aos mecanismos invariantes de mercado. $O$ administrador de cooperativas procurará desenvolver um sentido ético e estratégico bem apurado, pois a sua própria compreensão do que seja trabalho incorpora, como vimos, dimensões "metaeconômicas". Nisto reside, portanto, a raiz e o significado mais profundo da noção de liberdade, que faz com que as pessoas se contraponham às limitações que, em aparência, se manifestam como insuperáveis. Para o administrador autodeterminado, as situações-limite não são as barreiras intransponiveis onde todas as possibilidades acabam, mas as barreiras do real onde todas as possibilidades começam. "Ou, como diria Graciliano Ramos: "...quando nós assumimos voluntariamente o que nos condiciona, transformamos a estreiteza em profundidade". ${ }^{12}$

Desta maneira, um programa de desenvolvimento dos recursos humanos em uma cooperativa deve assumir uma orientação bem distinta das técnicas e práticas adotadas nas empresas comerciais típicas. Tal programa deverá ter por diretriz fundamental o desenvolvimento da autodeterminação dos atores cooperativistas. Para desenvolver esse programa, um esforço pioneiro, ou melhor, um exercício de auto-esclarecimento se faz necessário. Este demanda, pelo menos, três momentos de reflexão.

O primeiro momento partiu da definição dos participantes de uma cooperativa como pessoas autodeterminadas, capazes, portanto, de consciente e ativamente participarem na transformação do mundo em que vivem. $O$ segundo momento pode ser caracterizado pelo desenvolvimento de uma definição de administração de cooperativas que fosse capaz de expressar o critério de autodeterminação. O terceiro momento, de caráter mais prático, implica a criação de recursos estratégicos, ou seja, desenvolvimento de re- 
cursos humanos, reforma de estruturas administrativas, aperfeiçoamento de instrumentos administrativos, que são bases de apoio à viabilização de uma administração verdadeiramente cooperativista.

Assim, definiu-se administração como a descoberta e implementação de recursos estratégicos a serem mobilizados pelos participantes de uma cooperativa. Em outras palavras, administração é entendida como o processo social de revelação e realização de um curso de ação estratégica, seja ao nível macrossocial, seja ao nivel organizacional. Neste contexto, administrar significa tomar decisões críticas em relação a possiveis cursos de ação, isto é, decidir entre possibilidades objetivas emergentes. ${ }^{13}$

Coerente com o que vimos discutindo, diríamos que o desenvolvimento de recursos humanos em organizações cooperativas corresponde, em sua essência, a um processo de conscientização que procura desvendar a possibilidade de encontrar caminhos alternativos de desenvolvimento estratégico.

Neste sentido, um programa de treinamento de administradores de cooperativas daria ênfase, na fase inicial de conscientização, à análise daquelas "áreas de leitura" ou situações, que são indispensáveis à implementação de uma estratégia alternativa de desenvolvimento. Poderiam ser examinadas, por exemplo, as seguintes áreas: ${ }^{14}$

1. A posição horizontal da cooperativa, isto é, sua classificação (por critérios de produção, financeiros, ou de tamanho) em relação às demais cooperativas e outras empresas.

2. A diferenciação funcional da cooperativa, isto é, seu verdadeiro ramo de atividades e principais interfaces.

3. O contexto ou meio-ambiente imediato da cooperativa, isto é, aquela parte da sociedade global sobre a qual a instituição tem algum controle.

Neste ponto, é importante a análise de possiveis discrepâncias que possam existir entre: a) a identidade básica da cooperativa e sua clientela; b) os objetivos da cooperativa e seu meio-ambiente; c) os objetivos doutrinários e suas realizações concretas; d) os objetivos e a estrutura administrativa interna; e) os objetivos e os métodos utilizados.

4. A caracterização da estratégia da cooperativa e de seus pólos de tensão, isto é, qual seria a amplitude de sua ação planejada e de suas situações-limite.

A tensão que pode existir entre a cooperativa e seu contexto (ou a sociedade em geral) pode gerar vários pólos de tensão. Estes poderiam ser apreendidos, indagando-se sobre as seguintes questões: a) as necessidades básicas dos membros da cooperativa; b) as situações condicionantes, tais como o problema da autoridade, o problema do segredo, o problema do dinheiro; c) o grau de variedade requerida, isto é, a to- lerância interna ou externa aos diferentes padrões ou estilos de conduta; d) a dialética dos grupos, isto é, mecanismos de inclusão versus exclusão.

5. A caracterização da estrutura e processos internos da cooperativa.

Procurar-se-á examinar as seguintes subáreas: a) os procesos sociais conflitantes; b) os processos de redução cognitiva; c) a utilização de recursos especiais de análise.

Em sintese, este programa minimo de áreas de reflexão tem por objetivo sensibilizar os administradores de cooperativas para os problemas especificos dessas organizações. Objetiva, também, estudar, junto com os administradores, a viabilidade de um caminho alternativo de desenvolvimento estratégico.

Parece-nos claro que, para os objetivos desse trabalho, não é necessário considerarmos os detalhes práticos e os pormenores do presente programa. Isto poderá ser feito no futuro. Contudo, seria oportuno enfatizar, uma vez mais, que a presente proposta não segue a orientação usual de treinamento que, inconscientemente, acaba por transformar as pessoas em simples "receptáculos de cargos" (jobholders), mas, muito pelo contrário, propõe-se estimular o desenvolvimento de sujeitos ativos e conscientes, imbuidos do ideal cooperativista.

\section{OS REQUISITOS DE UM PROGRAMA DE DESENVOLVIMENTO DE ESTRUTURAS ADMINISTRATIVAS EM COOPERATIVAS}

Vimos que o projeto cooperativista - no seu sentido mais prof undo - implica considerar seus integrantes como seres humanos autodeterminados, sujeitos ativos e conscientes, capazes, portanto, de participar na transformação do mundo em que vivem. Isto significa que entre os membros da cooperativa e suas estruturas administrativas existe uma relação de tensão constante e dinâmica. $O$ ator cooperativista se recusa a ser reduzido a uma simples descrição de cargos, funções ou a um formato administrativo rígido. A sua ação pressupõe, é óbvio, um sistema organizado de tarefas, mas, esta se manifesta - na sua expressão mais consciente - como o resultado do confronto entre aquilo que o o sujeito, dentro de um dado sistema administrativo, pode fazer, deve fazer e, realmente faz e os atos que lhe são prescritos pela doutrina cooperativista. ${ }^{15}$

Assim, ao concebermos sistemas administrativos para as cooperativas, deve-se considerar dois pólos de legitimação: os homens e as estruturas. Tradicionalmente, o que se faz em termos de design administrativo é projetar uma estrutura de cargos e de tarefas a partir de determinados critérios funcionais $\mathrm{e}$, daí em diante, tentar ajustar as pessoas e as suas atividades às necessidades do sistema administrativo. Muito pelo contrário, o design de sistemas administrativos em cooperativas não é uma tarefa de tecnocratas; isto 
porque, sujeitos ativos e conscientes criam e recriam as suas próprias condições de trabalho, conferindo a este último uma dimensão extremamente rica e complexa. Sem entrarmos em maiores detalhes. poder-seia adiantar que o design administrativo em cooperativas assume o dilema entre o que se pode fazer, deve fazer e realmente se faz e certos valores normativos. ${ }^{16}$

Nessa perspectiva, poderíamos citar, à guisa de exemplo, os seguintes valores norteadores do design em uma cooperativa:

1. O trabalho nas cooperativas deve exigir das pessoas algo mais do que uma simples resistência física ou tolerância à rotina, propiciando, assim, um minimo de variedade.

2. As pessoas em uma cooperativa devem aprender com a experiência do seu trabalho e ter condições para continuar aprendendo.

3. O trabalho nas cooperativas deve conter uma área de decisão própria, de exclusiva responsabilidade de seus executantes.

4. As cooperativas devem promover um mínimo de apoio social e reconhecimento existencial em seus locais de trabalho.

5. As pessoas em uma cooperativa devem poder e saber relacionar o que elas fazem e o que produzem com o conjunto de sua vida social.

6. As pessoas em uma cooperativa devem poder relacionar o seu trabalho com algum projeto futuro (não necessariamente carreira e promoção). ${ }^{17}$

Se o design administrativo incorporar esses valores normativos, poderíamos ter um considerável enriquecimento do trabalho nas cooperativas, o qual se expressaria do seguinte modo:

a) estabelecimento de maior e melhor variedade nas tarefas produtivas;

b) delineamento de uma sequiência de tarefas que propicie maior integração social e maior inteireza existencial;

c) estabelecimento de períodos de tempo mais favoráveis para um determinado ciclo de trabalho;

d) determinação de padrões objetivos de quantidade e qualidade indispensáveis a qualquer processo de conhecimento;

e) diversificação de atividades produtivas em virtude da inclusão de tarefas auxiliares e de preparação;

f) valorização de certas atividades produtivas pela inclusão, em graus variáveis, de componentes como: cuidado, habilidade, conhecimento, que são socialmente desejáveis e existencialmente importantes em qualquer comunidade de pessoas; g) alteração dos padrões correspondentes a: integração de tarefas, rotação de cargos e proximidade física, onde as atividades de produção forem submetidas a elevados graus de tensão psicciógica;

h) modificação da estrutura de tarefas produtivas em função da contribuição, socialmente desejável. do trabalho individual ao produto final de uma organização;

i) diversificação dos canais de comunicação. ${ }^{18}$

Cremos que para os objetivos desse trabalho não seria necessário descrevermos as diferentes etapas do design administrativo. Apenas mencionariamos que um dos métodos mais promissores de design utiliza, comumente, nove etapas-padrão ou procedimentos formais. ${ }^{19}$

Em resumo, o que estamos chamando de desenvolvimento de recursos estratégicos implica o desdobramento de três processos básicos:

1. O desenvolvimento dos recursos humanos: através da leitura crítica dos meios de articulação da cooperativa na sociedade global e das suas condições de vida e de trabalho. Espera-se que, após este processo de conscientização, os membros de uma cooperativa tenham podido adquirir uma nova compreensão sobre o verdadeiro significado das organizações cooperativas e de seu trabalho dentro delas. Este seria o primeiro passo para uma inteligente mobilização dos recursos administrativos internos. Deste modo, já estaríamos ingressando na segunda fase.

2. O desenvolvimento de estruturas administrativas: através de um novo design a ser proposto por sujeitos conscientes e ativos, capazes de formularem projetos conseqüentes e realistas. Uma vez fortalecidas as condições internas da organização, o que pressupõe maior capacidade para reagir e intervir junto a realidade, será considerado a fase seguinte.

3. O desenvolvimento de políticas e de instrumentos estratégicos: através do exame dos métodos particulares de intervenção em uma dada realidade. Ou seja, procura-se refletir sobre as práticas especificas de uma cooperativa em seu contexto imediato. Neste ponto, e articulando-se às fases anteriores, será examinada, junto com os atores cooperativistas, a possibilidade de se desenvolverem vias alternativas de alocação de recursos ou de formulação de políticas administrativas.

Assim, à guisa de sugestão, poder-se-ia considerar as seguintes politicas alternativas:

1. Em relação à política de produtos ou serviços; as cooperativas deveriam explorar a possibilidade de uma política baseada no valor intrínseco e nas reais dimensões de seus produtos ou serviços. Para o estabelecimento de uma sólida e duradoura reputação, o conteúdo real das coisas acaba prevalecendo sobre a utilização pura e simples de imagens. 
2. Em consequiência, a política de comunicação social das cooperativas, deveria se basear na concessão de informações reais e honestas sobre seus produtos. Por exemplo, uma cooperativa de consumo na Califórnia costuma fazer a avaliação de seus produtos da seguinte maneira: "O teor protéico do produto $A$ é equivalente ao do produto $B$; contudo, a qualidade dos seus aminoácidos é bem superior", dando, assim, uma orientação segura aos seus consumidores.

3. Em relação à política de comercialização: as cooperativas deveriam contemplar a possibilidade de atuarem no chamado mercado institucional (hospitais, universidades, escolas, forças armadas, clubes, etc.), onde as vendas podem ser realizadas em bases contratuais.

4. As cooperativas deveriam estimular a criação de canais alternativos de distribuição, tais como: "cooperativas de famílias", "clubes de compra", "cadeias de consumidores", "unidades móveis", etc.

5. As cooperativas deveriam promover a integração da produção e da distribuição, através das trocas entre cooperativas.

6. As cooperativas deveriam desenvolver estruturas administrativas que permitissem uma confederação de cooperativas, preservando, contudo, o caráter independente, democrático e local das cooperativas filiadas.

7. As cooperativas deveriam fazer um esforço consciente e permanente de desenvolvimento de seus recursos estratégicos.

Para concluir, ressaltamos, uma vez mais, que o presente trabalho trata apenas dos requisitos, ou das diretrizes e bases, que devem orientar um programa de treinamento que tenha o propósito de valorizar as características particulares de uma cooperativa. $\mathrm{Na}$ da foi dito sobre os detalhes e procedimentos específicos desse programa. Insistimos, contudo, que tal programa se baseia na conscientização dos atores cooperativistas em relação aos seus problemas imediatos de vida e de trabalho. para que isso se realize é necessário proceder a um levantamento do universo vocabular e temático dos participantes e relacioná-los com as áreas de reflexão já mencionadas. Este constitui o material básico que será codificado de alguma forma, visual ou gráfica, e que servirá de suporte fundamental ao processo de conscientização. Os prazos e o número de pessoas envolvidas nesse processo dependerão dos recursos disponíveis e da magnitude que se queira emprestar a esse programa: se uma cooperativa ou a um conjunto de cooperativas regionais. De qualquer forma, os conceitos geradores do aprendizado serão sempre adequados a cada cooperativa individual; o que implica sempre um levantamento específico para cada cooperativa.

Concluida esta etapa de leitura crítica da realidade interna e externa da cooperativa (veja a parte referen- te a "áreas de leitura") e que constitui o módulo 1 de nosso programa, os participantes teriam condições para se envolver com o módulo 2 , ou seja, o design de estruturas administrativas (veja a parte referente a etapas do design administrativo). Fortalecida, assim, as condições de organização da cooperativa, o programa passaria a se interessar por instrumentos ou técnicas específicas de intervenção, o que constitui o módulo 3 de nosso programa.

O detalhamento de cada módulo constitui o programa de treinamento propriamente dito, e poderá ser realizado caso os valores e os requisitos estabelecidos por este trabalho sejam de franca aceitação. 1 Veja Schaaf, Michael. Cooperatives at the crossroads: the po-
tential for a major new economic and social role. Exploratory Pro-
ject for Economic Alternatives. p. 5 .

2 Veja Polanyi, Karl. The Great transformation: the political and economic origins of our time. Beacon Press, 1957.

3 Veja Colombain, M. From the Rochdale Rules to the principles of cooperative. Cooperative Information. Escritório Internacional do Trabalho, Organização das Nações Unidas.

4 Lembramos, uma vez mais, que estamos tratando das cooperativas enquanto um tipo organizacional diferenciado; portanto, essas considerações se aplicariam a qualquer cooperativa, sejam elas de produtores, de consumo, mistas, de serviços ou artesanais.

5 Veja Schaaf, Michael. op. cit. p. 112.

6 Id. ibid. p. 116. 
7 Veja Henderson, Hazel. Creating alternative futures. Berkeley, 1978. p. 83-91.

${ }^{8}$ Kosik, Karel. A Dialética da moral e a moral Dialética. In Moral e Sociedade. Rio de Janeiro, Paz e Terra, 1969. p. 105-6.

9 Veja Debrun, Michel. O Fato politico, Rio de Janeiro, Fundação Getúlio Vargas, 1962.

10 Veja Warbasse, James Peter. Problems of cooperation, New York, Island Press, 1942; e Pinho, Diva Benevides. Cooperativase desenvolvimento econômico. São Paulo, 1962.

11 Pinto, Álvaro Vieira. Consciência e realidade nacional. Apud Freire, Paulo. Pedagogy of the opressed. The Seabury Press, 1970. p. 89.

12 Apud Guerreiro Ramos. Introdução crítica à sociologia brasileira. Andes, 1957. p. 33.

13 Guerreiro Ramos. Administração e estratégia do desenvolvimento. Rio de Janeiro, Fundação Getulio Vargas, 1966. p. 205-6.

14 Aqui, iremos dar apenas um resumo do que se poderia chamar de "áreas de leitura" do diagnóstico. Nosso artigo A Base de uma administração autodeterminada: o diagnóstico emancipador, publicado pela Revista de Administração de Empresas, 20 (2), 1980, desenvolve em detalhes o presente tema.
15 Esta contradição manifesta entre os determinismos da economia e os atos de liberdade, que é vivenciada por todos nós, é muito bem analisada por Kosik, Karel. op. cit. p. 105-7.

16 A questão do design administrativo é melhor tratada em nosso artigo Abordagem sociotécnica: um rápido balanço, publicado pela Revista de Administração de Empresas, 20 (3), 1980.

17 Esta lista de valores é uma versão muito modificada de Cherns, Albert. The Principles of socio-technical design. Los Angeles, Escola Graduada de Administração da Universidade da Califórnia, p. 14.

18 Modificado de Thorsrud, Einar. Job design in the wider context. In: Davis, Louis E. \& Taylor, James C. Design of jobs. Penguin Books, 1972. p. 455-7.

19 As etapas de análise consideradas por este método são, usualmente, as seguintes: avaliação inicial; identificação das operações primordiais; identificação das variações primárias e suas possíveis interações; análise do sistema social; determinação da percepção dos participantes em relação aos papéis sociais a serem desempenhados; determinação dos sistemas de apoio; especificação dos sistemas fornecedores e usuários; avaliação do impacto provocado por iniciativas especiais de desenvolvimento; propostas para a mudança. Estas etapas da análise sociotécnica são descritas em maiores detalhes em nosso artigo: Abordagem sociotécnica: um rápido balanço. op. cit. 